\title{
Case Presentation of Preureteral Vena Cava and Review of the Literature
}

\author{
Nexhmi Hyseni*, Sadik Llullaku, Murat Berisha, Ardian Shefkiu, Salih Grajqevci, Hysni Jashari, \\ Defrim Koqinaj, Fjolla Hyseni, Islam Bytyci, Fehim Muqolli \\ Department of Pediatric Surgery, University Clinical Center, Prishtina, Kosovo \\ Email: *nexhmi_h@yahoo.com
}

Received July 24, 2013; revised August 21, 2013; accepted August 26, 2013

Copyright (c) 2013 Nexhmi Hyseni et al. This is an open access article distributed under the Creative Commons Attribution License, which permits unrestricted use, distribution, and reproduction in any medium, provided the original work is properly cited.

\begin{abstract}
Retrocaval ureter, terms are anatomically descriptive but misleading in regard to development and results from altered vascular development. This anomaly is relatively uncommon, although it has clinical relevance. The ureter typically deviates medially behind the inferior vena cava, winding about and crossing in front of it from a medial to a lateral direction, to resume a normal course, distally, to the bladder. The renal pelvis and upper ureter typically appear elongated and dilated in a " $\mathrm{J}$ " or fishhook shape before passing behind the vena cava. Diagnoses were confirmed with intravenous urography and patient had an open surgical repair of the anomaly. The anomaly predominantly involves the right ureter, as was observed in these reported cases. Treatment is surgical allowing for correction of the anomaly with resolution of symptoms
\end{abstract}

Keywords: Preuretral Vena Cava; Pediatric Urology

\section{Introduction}

This anomaly is commonly known as circumcaval or retrocaval ureter. This variety of vascular lesion can cause ureteral obstruction. The term preurteral vena cava emphasizes that the circumcaval ureter results from altered vascular, rather than uretral, development [1].

It was initially considered as aberration in ureteric development; however several studies in embryology have led to it being considered as an aberration in the development of the inferior vena cava [2-4].

This disorder involves the right ureter, which typically deviates medially behind (dorsal to) the inferior vena cava, winding about and crossing in front of it from a medial to lateral direction, to resume a normal course, distally, to the bladder. The renal pelvis and upper ureter are typically elongated and dilated in a $\mathrm{J}$ or fishhook shape before passing behind the vena cava [5].

\section{Case Report}

A 5 year-old boy since four months, he admitted having had occasional sharp transient dull and intermittent pain in the right flank.

Physical examination was normal. Complete labora-

${ }^{*}$ Corresponding author. tory evaluation including urinalysis, complete blood picture, urea, creatinine and electrolytes were within normal limits. KUB ultrasound showed a moderate hydronephrosis. Left kidney, left ureter and urinary bladder were normal. An intravenous pyelogram showed prompt bilateral excretion from both kidneys and a normal left upper urinary tract. On the right side a moderate hydronephrosis associated with caliectasis was observed and it was noted that the upper ureter was S-shaped and was kinked medially towards the midline at the level of the transverse process of the third lumbar vertebra. The ureter could not be visualized beyond that point Figure 1. Retrograde ureteropyelography demonstrates and S curve to the point of obstruction, with the retrocaval segment lying at the level of L3 or L4 suggesting the presence of a retrocaval ureter (Figure 2). The right ureter was explored through a right-flank incision. On exploration, proximal ureter was curved medially then posterior to IVC. Finally curved anteromedially to IVC and took a downward course (Figure 3). Surgical correction involves ureteral division, with relocation and ureteroureteral reanastomosis Figure 4. A simple ureteral stent was inserted in an antegrade manner during operation. An intravenous pyelography, and renal ultrasonography were performed 3 months postoperatively, showed regression 


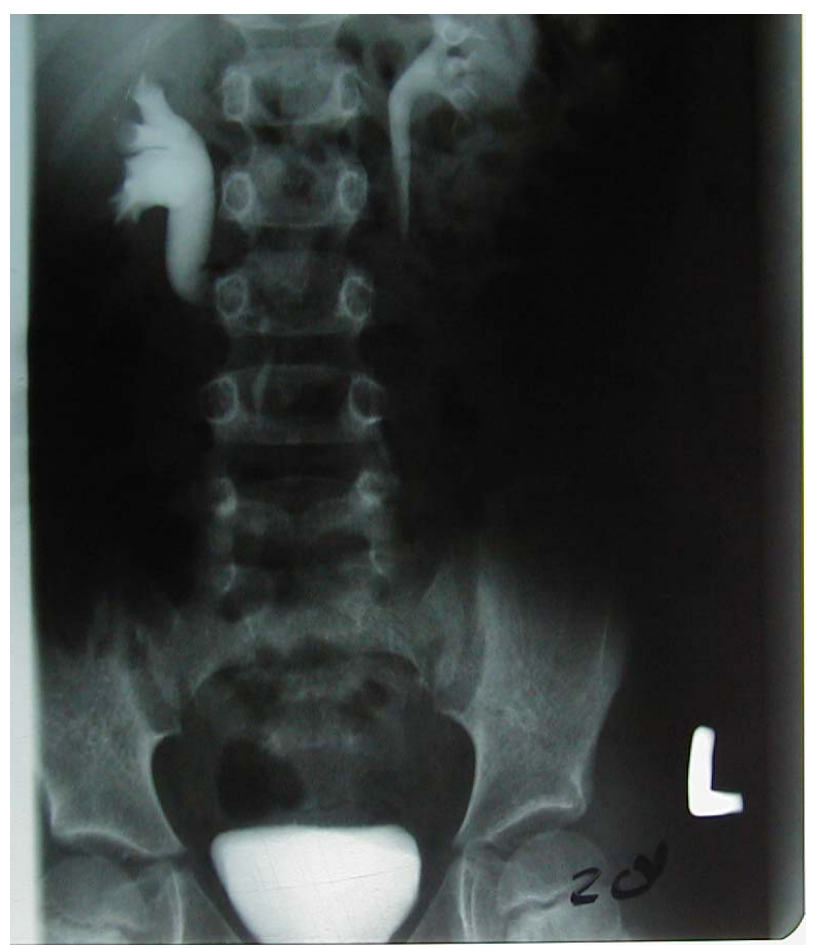

Figure 1. Intravenous pyelogram showed that the upper ureter was S-shaped and was kinked medially towards the midline at the level of the transverse process of the third lumbar vertebra.
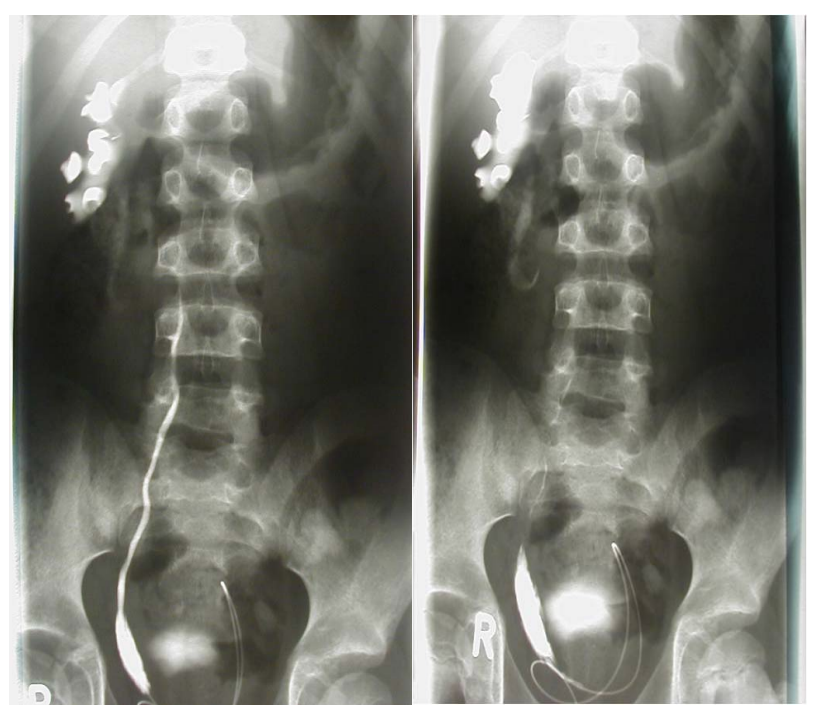

Figure 2. Retrograde ureteropyelography demonstrates an $S$ curve to the point of obstruction, with the retrocaval segment lying at the level of L3 or L4 suggesting the presence of a retrocaval ureter.

of hydronephrosis and hydroureter with no ureteric obstruction.

\section{Discussion}

The first observed case of retrocaval ureters was de- scribed by Hochstetter in 1893 [6]. Though initially thought of as an anomaly of ureteric development studies in embryology has revealed an anomaly related to the development of the inferior vena cava [7-9].

This anomaly is commonly known as circum-caval or retrocaval ureter [5]. The terms of cicumcaval ureter is preferred, because rarely a ureter may lie behind (dorsal to) the vena cava for some portion of its lumbar course, forming a "siphon" capable of causing urinary obstruction. The anomaly predominantly involves the right ureter, as was observed in these our reported cases. If it involves the left ureter then it is usually associated with

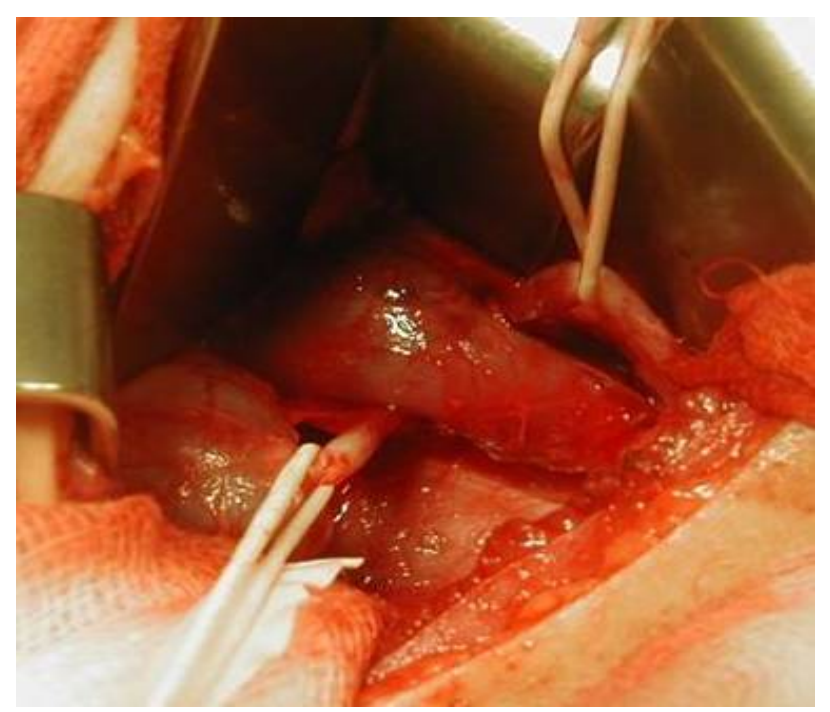

Figure 3. On exploration, proximal ureter was curved medially then posterior to IVC and finally curved anteromedially to IVC and took a downward course.

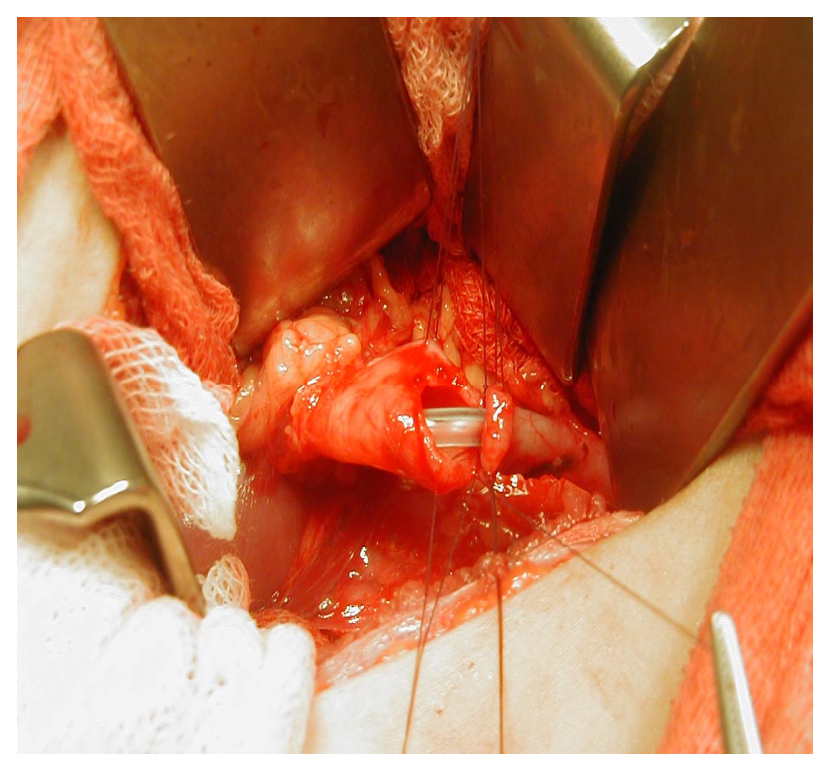

Figure 4. Following the confirmation of obstruction, surgery was indicated in the form of pyelic sectioning and ureteral trans positioning of the retrocaval segment. 
either partial or complete situs inversus or duplication of the inferior vena cava (IVC) $[10,11]$. Duplication of the IVC (D-IVC): This is a relatively uncommon congenital anomaly with a reported incidence of $0.2 \%-3 \%$. A majority of the cases are clinically silent and they are diagnosed incidentally during imaging studies which are done for other reasons [12]. Retrocaval ureter results from altered vascular, rather than ureteral, development. Bateson and Atkinson distinguished the two types of retrocaval ureters according to the radiological appearance and the site of the ureteral narrowing. These are:

Type I: The ureter crosses behind the IVC, at the level of the L3 vertebra and it exhibits an "S-shaped" deformity.

Type II: The renal pelvis and the upper ureter lie horizontally. The retrocaval segment of the ureter is at the same level as that of the renal pelvis and it exhibits a "sickle shaped" deformity [13].

The retrocaval ureter which was observed in our case classified into the Type I of the given classification. The incidence of preuretral vena cava at autopsy is about one in 1500 cadavers, although the lesion is congenital, most patients do not present until the third or fourth decade of life [5]. Clinically, may present with symptoms of flank or abdominal pain or infection or the disorder may be discovered incidentally during other radiologic tests. This disorder can cause varying degrees of ureteral obstruction. In order to reduce irradiation, the scintigraphy scan is likely to replace IV urography, CT urography and diuretic renography. Excretory urography often fails to visualize the portion of the ureter beyond the $\mathrm{J}$ hook, but retrograde ureteropyelography demonstrates an $\mathrm{S}$ curve to the point of obstruction with the reterocaval ureter lying at the level of L3 or L4 [14].

In our cases Intravenous pyelogram showed that the upper ureter was S-shaped and was kinked medially towards the midline at the level of the transverse process of the third lumbar vertebra. Also we perform the retrograde ureteropyelography and demonstrate the S curve of retrocaval ureter. MRI can demonstrate the course of a preureteral vena cava, and may be a more detailed and less invasive imaging procedure, compared with CT and retrograde Pyelography [15]. Surgical repair is indicated only when symptoms are present or significant obstruction exist that have repercussion in renal function. Surgical correction involves ureteral divisions, with relocation and ureteroureteral or ureteropelvic reanastomosis [16, 17]. Laparoscopic and robotic minimally invasive repair of the ureter has been described by a trans or retroperitoneal approach and should be considered before open surgery $[18,19]$. In our cases following the confirmation of obstruction, surgery was indicated in the form of proximal ureteric sectioning and ureteral transpositioning of the retrocaval segment.

\section{Conclusion}

Retrocaval ureter should be suspected in any case of pyelectasis and proximal ureterectasis respectively of the upper third ureter on the right side.

\section{REFERENCES}

[1] S. H. Kim, "Retrocaval Ureter,” In: K. W. Ashcraft and T. M. Holder, Eds., Pediatric Surgery, W.B. Saunders, Philadelphia, 1993, p. 603.

[2] V. P. Chuang, C. E. Mena and P. A. Hoskins, “Congenital Anomalies of the Inferior Vena Cava. Review of Embryogenesis and Presentation of a Simplified Classification,” British Journal of Radiology, Vol. 47, No. 556, 1974, pp. 206-213. doi:10.1259/0007-1285-47-556-206

[3] R. N. Schlussel and A. B. Retik, "Preureteral Vena Cava,” In: L. R. Kavoussi, A. C. Novick, A. W. Partin and C. A. Peters, Eds., Campbell-Walsh Urology, ElSevier Saunders, Philadelphia, 2007, pp. 3418-3420.

[4] A. Lesma, A. Bocciardi and P. Rigatti, "Circumcaval Ureter: Embryology,” European Urology Supplements, Vol. 5, No. 5, 2006, pp. 444-448.

[5] C. A. Peters, R. N. Schlussel and C. Mendelson, "Preureteral Vena Cava,” In: A. J. Wein, L. R. Kavoussi, A. C. Novick, A. W. Partin, C. A. Peters, Eds., Campbell-Walsh Urology, El-Sevier Saunders, Philadelphia, 2012, pp. 3263-3265.

[6] R. O. Olson and G. Austen Jr., "Postcaval Ureter-Report and Discussion of a Case with Successful Surgical Repair," The New England Journal of Medicine, Vol. 242, No. 25, 1950, pp. 963-968. doi:10.1056/NEJM195006222422501

[7] W. Dreyfuss, “Anomaly Simulating a Retrocaval Ureter," Journal of Urology, Vol. 82, 1959, pp. 630-632.

[8] I. Lerman, S. Lerman and F. Lerman, "Retrocaval Ureter: Report of a Case,” The New England Journal of Medicine, Vol. 53, 1956, p. 74.

[9] M. R. Peisojovich and S. J. Lutz, "Retrocaval Ureter-A Case Report and a Successful Repair with a New Surgical Technique,” Michigan Medicine, Vol. 68, No. 21, 1969, pp. 1137-1141.

[10] M. Watanabe, S. Kawamura, T. Nakada, et al., "Left Preureteral Vena Cava (Retrocaval or Circumcaval Ureter) Associated with Partial Situs Inversus,” Journal of Urology, Vol. 145, 1991, pp. 1047-1048.

[11] I. Rubinstein, A. G. Calvacanti, A. F. Canalini, M. A. Freitas and P. M. Accioly, "Retrocaval Ureter: Two Case Reports,” Ghana Medical Journal, Vol. 45, No. 4, 2011, pp. 177-180.

[12] W. T. Ng and S. S. M. Ng, "Double Inferior Vena Cava: A Report of Three Cases," Singapore Medical Journal, Vol. 50, No. 6, 2009, pp. 211-213.

[13] E. Bateson and D. Atkinson, "Circumcaval Ureter: A New Classification,” Clinical Radiology, Vol. 20, No. 2, 1969, pp. 173-177. doi:10.1016/S0009-9260(69)80166-2

[14] M. M. Kenawi and D. I. Williams, "Circumcaval Ureter: A Report of 4 Cases in Children with a Review of the 
Literature and a New Classification,” British Journal of Urology, Vol. 48, No. 3, 1976, pp. 183-192. doi:10.1111/j.1464-410X.1976.tb10197.x

[15] M. C. Uthapp, et al., "Retrocaval Urter: MR Appearances,” British Journal of Radiology, Vol. 75, No. 890, 2002, pp. 177-179.

[16] S. K. Acharya, B. Jindal, D. K. Yadav, S. Singha and D. Bagga, "Retrocaval Ureter: A Rare Cause of Hydronephrosis in Children," Journal of Pediatric Surgery, Vol. 44, No. 4, 2009, pp. 846-848. doi:10.1016/j.jpedsurg.2008.11.053

[17] P. A. López González, P. López Cubillana, G. Server Pastor, O. Girón Vallejo, R. Ruíz Pruneda, G. Doñate Iñiguez, J. C. Ruíz Morcillo, C. Moreno Alarcón, L. Nortes Cano and G. Gómez Gómez, "Retrocaval Ureter in Chil- dren. Case Report and Bibliographic Review,” Archivos Españoles de Urología, Vol. 64, No. 5, 2011, pp. 461464.

[18] H. Z. Li, X. Ma, L. Qi, T. P. Shi, B. J. Wang and X. Zhang, "Retroperitoneal Laparoscopic Ureteroureterostomy for Retrocaval Ureter: Report of 10 Cases and Literature Review,” Urology, Vol. 76, No. 4, 2010, pp. 873876. doi:10.1016/j.urology.2009.12.056

[19] Z. Chen, X. Chen, Z. H. Wu, Y. C. Luo and N. N. Li, "Treatment of Retrocaval Ureter by Retroperitoneal Laparoscopic Ureteroureterostomy: Experience On $12 \mathrm{~Pa}-$ tients,” Journal of Laparoendoscopic \& Advanced Surgical Techniques A, Vol. 21, No. 9, 2011, pp. 803-807. doi:10.1089/lap.2011.0211

\section{Abbreviations}

IVC: Inferior Vena Cava

D-IVC: Duplication of the IVC

KUB: Kidney Urinary Bladder 